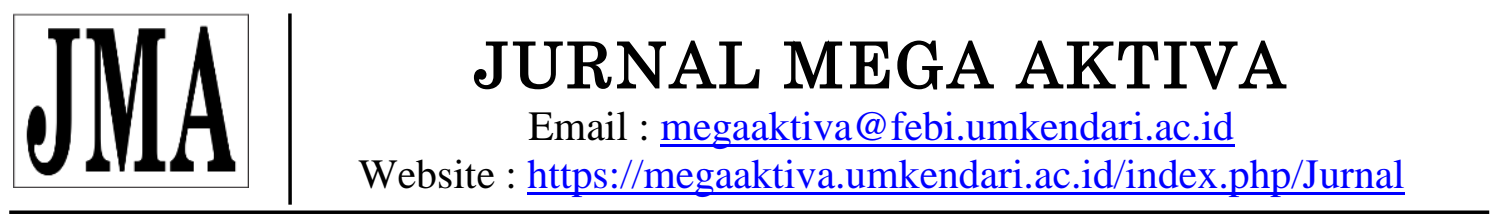

\title{
PENGEMBANGAN WILAYAH BERBASIS POTENSI SEKTOR UNGGGULAN DI KABUPATEN GOWA
}

\author{
${ }^{1}$ Edo Pramana Putra, ${ }^{2}$ Kasmiati \\ ${ }^{1}$ Peneliti di Pusat Pendidikan dan Penelitian Pembangunan Indonesia (P41), Bogor \\ Email : edopramanaputra@gmail.com \\ ${ }^{2}$ Peneliti Pusat Studi Ekonomi dan Kebijakan Publik (PSEKP) FEBI-UMK \\ Email : kasmiati.10.s@gmail.com
}

\begin{abstract}
ABSTRAK
Kebijakan pengembangan wilayah berdasarkan potensi sektor unggulan selama ini belum disesuaikan dengan daya dukung daerah, ditambah dengan belum tersedianya data sebaran komoditi unggulan daerah yang berbasis sistem informasi geografis (GIS) termaksud di Kabupaten Gowa. Oleh sebab itu penelitian ini bertujuan untuk menentukan komoditi unggulan di Kabupaten Gowa, serta memetakan sebaran komoditi unggulan di tiap Kecamatan di Kabupaten Gowa yang dapat menjadi dasar kebijakan pengembangan wilayah di Kabupaten Gowa. Alat analisis yang digunakan adalah Tipologi Klassen untuk mengklasifikasikan Pola Pertumbuhan Sektor Ekonomi Kabupaten Gowa dan analisis LQ untuk menentukan sektor unggulan. Lalu digunakan analisis deskriptif dan GIS untuk menjabarkan dan melihat sebaran subsektor yang cocok di tiap wilayah. Hasil analisis Tipologi Klassen menunjukkan sektor pertanian merupakan sektor yang maju tapi tertekan, kontribusi sektor pertanian dalam perekonomian Kabupaten Gowa sangat besar yaitu 44\% (2009-2013. Namun berdasarkan Hasil analisis Loqation Quotient (LQ) sektor pertanain merupakan sektor unggulan bersama dengan beberapa sektor lain seperti keuangan, real estat dan jasa perusahaan, serta sektor jasa-jasa. Dalam rangak pengembankan wilayah berkelanjutan di Kabupate Gowa maka sektor pertanian masih layak dijadikan sebagai sektor unggulan mengingat sektor pertanian juga masih mendominasi sumber pendapatan masyarakat.
\end{abstract}

Kata Kunci : Pengembangan Wilayah, Sektor Unggulan, Tipologi, Location Quotient dan Pertanian

\section{ABSTRACT}

Regional development policy that based on leading sector potentials had not been adapted to the carryng capacity of the area in Gowa. moreover, the data distribution of regional commodity-based geographic information system (GIS) was unavailable. Therefore, this study aimed to determine the commodity in Gowa, and map distribution of commodity in each district in Gowat that could be the basis for regional development policies in the region. The analytical tool used was the Klassen Typology which classified the economic sector growth patterns in Gowa and Location Quation (LQ) analysis to determine the leading sectors. Then, the descriptive analysis and GIS were carried and see distribution of sub-sectors that aproppriate in each region. Klassen typology analysis results show, the agricultural sector is an advanced sector but deprssed, contribute the economy of Gowa in very large scale of 44\% (from 2009 to 2013). However, based on the results of the analysis $L Q$ not only agricutural sector come out leading sectors including finance, real estate and business services sector. On the frame of sustainability 
\begin{tabular}{l|l|} 
JII & $\begin{array}{c}\text { JURNAL MEGA AKTIVA } \\
\text { Email : megaaktiva@febi.umkendari.ac.id } \\
\text { Website }: \text { https://megaaktiva.umkendari.ac.id/index.php/Jurnal }\end{array}$ \\
\hline
\end{tabular}

development in Gowa, the agricutural is still eligible as leading sector, sice the sector is still dominated the source of income.

Keywords : Regional Development, leading Sectors, typology, Location Quotient and Agriculture

\section{PENDAHULUAN}

Pembangunan wilayah merupakan pembangunan ekonomi dengan mempertimbangkan variabel tempat dan waktu. Karakteristik fisik dan sosial wilayah di Indonesia yang beragam memberikan berbagai potensi wilayah berbeda. Perbedaan potensi wilayah di Indonesia menyebabkan terjadinya kesenjangan, baik itu kesenjangan antar wilayah, kesenjangan antar desa dan kota, maupun kesenjangan antara golongan pendapatan (Nindyantoro, 2004). Menurut Antonescu (2012) kesenjangan antar wilayah dan di dalam wilayah terjadi akibat konsentrasi, aglomerasi, tren yang dipicu oleh fenomena eksternal, globalisasi, integrasi, atau fenomena internal, clustering, munculnya kutub pertumbuhan / pengembangan, keterlibatan lembaga lokal dalam berbagai aspek kehidupan ekonomi, dan lain-lain.

Oleh sebab itu wilayah harus benar-benar dibangun dengan mempertimbangkan berbagai aspek fisik, sosial ekonomi budaya dan sumberdaya alam, terutama dalam proses pemanfaatanya harus mampu mendorong wilayah sekitarnya ikut tumbuh dan berkembang, bukanya melanggengkan hubungan yang bersifat menghisap antara satu wilayah dan wilayah lainya terutam antara wilayah inti dan phery-phery. Di Kawasan Timur Indonesia (KTI) salah satu wilayah yang mempunyai peran besar adalah Provinsi Sulawesi Selatan yang dapat dilihat melalui besarnya transaksi barang dan jasa yang keluar dan masuk ke Provinsi Sulawesi Selatan (Bappenas, 2008). Besarnya peran Provinsi Sulawesi Selatan terhadap perekonomian wilayah di KTI didukung oleh besarnya peran wilayah-wilayah didalamnya, baik kabupaten/kota. Wilayah-wilayah perkotaan di Provinsi Sulawesi Selatan (core region) berperan sebagai pusat perdagangan dan jasa, pusat pemerintahan dan pemukiman, sedangkan wilayah disekelilingnya (hinterland) berfungsi sebagai pemasok barang dan jasa ke wilayah inti, bahkan keluar daerah provinsi Sulawesi Selatan.

Salah satu wilayah hinterland ibukota Provinsi Sulawesi Selatan (Kota Makassar) adalah Kabupaten Gowa mempunyai luas wilayah $1.888,33 \mathrm{~km}^{2}$ berbatasan dengan Kabupaten Sinjai, Bulukumba, dan Bantaeng di sebelah timur, Kabupaten Takalar dan Jenoponto di sebelah selatan. Berbatasan langsung dengan Kota Makassar dan Kabupaten Takalar di sebelah barat, sebelah utara berbatasan langsung dengan Kota Makassar dan Kabupaten Maros. Letak geografis Kabupaten Gowa merupakan suatu kelebihan karena berbatasan langsung dengan beberapa daerah yang menjadi bagian dari kawasan Mamminasata. Mamminasata merupakan konsep untuk membangun wilayah metropolitan di Sulawesi Selatan dengan menggabungkan beberapa wilayah kabupatenkota seperti "Makassar, Maros, Sungguminasa, dan Takalar" keputusanyan berdasarkan Perpres nomor 55 tahun 2011. Hal ini tentu memudahkan akses dan mobilitas barang dan jasa untuk diperjualbelikkan.

Hingga saat ini daerah yang masuk dalam kawasan pengembangan metropolitan Mamminasata ternyata mempunyai tingkat perkembangan yang berbeda-beda. 
berdasarkan penelitian Bakri et al (2016) yang menggunakan Tipologi Klassen untuk melihat tingkat kemajuan setiap wilayah di Kawasan Mamminasata menempatkan kabupaten Gowa pada kuadran IV sebagai daerah relatif terbelakang yang berarti perolehan laju pertumbuhan ekonomi dan pendapatan perkapita Kabupaten Gowa masih lebih kecil dibandingkan dengan rata-rata pertumbuhan ekonomi dan pendapatan perkapita dari Kota Makassar, Kabupaten Maros, dan Kabupaten Takalar.

Oleh sebab itu Kabupaten Gowa perlu dibangun berdasarkan pada sektor basis. Mengingat salah satu pendekatan makro untuk mengatasi masalah kesenjangan adalah memacu pertumbuhan ekonomi wilayah dengan penetapan sektor unggulan (basic sector), selain itu sektor unggulan juga berfungsi untuk menciptakan dan memperluas lapangan kerja yang dapat mendorong peningkatan pendapatan perkapita yang pada akhirnya dapat mengurangi kesenjangan antara daerah dikawasan Mamminasata, karena saat ini tingkat disparitasnya masih tergolong tinggi dengan nilai Indeks Wililamson > 0,36 (Bakri et al, 2016). Oleh sebab itu penentuan sektor unggulan di Kabupaten Gowa sangat diperlukan untuk untuk dijadikan dasar pengambilan kebijakan, pengembangan sektoral maupun pengembangan wilayah, sehingga perekonomian Kabupaten Gowa dapat tumbuh dengan cepat dan memberikan dampak terhadap akselerasi perekonomian Provinsi Sulawesi Selatan.

\section{KAJIAN TEORITIS}

Wilayah tidak dapat dibangun secara serampangan dalam arti suka-suka pemerintah atau tanpa perencanaan. Tetapi harus memperhatikan karasteristik dan potensi utama suatu wilayah. Kedua hal ini merupakan landasan untuk membentuk perencanaan wilayah yang kokoh dan holistik. Perencanaan wilayah sendiri dapat dimaknai sebagai perencanaan ekonomi yang menekankan pada masalah lokasi atau ruang di mana aktivitas ekonomi tersebut berada (Nurzaman, 2012). Dengan perencanaan wilayah yang matang diharapkan mampu menopang pengembangannya secara berkelanjutan. Berdasarkan kajian literatur yang dilakukan oleh Nurzaman (2012)yang juga mengutip Norton (2003) bahwa terdapat 6 unsur utama dalam mengembangkan pembangunan berkelanjutanpada tingkat lokal yaitu :

a. Mempromosikan pengembangan penggunaan lahan yang selaras dengan alam.

b. Mempromosikan penggunaan pengembangan lahan yang memfasilitasi lingkungan terbangun yang layak untuk hidup.

c. Mempromosikan pengembangan ekonomi berbasis setempat.

d. Mempromosikan kesamaan dan keadilan dalam akses terhadap sumber daya ekonomi dan sosial.

e. Menganut kebijkan dimana pihak pencemar membayar biaya dan kerusakan yang mereka lakukan.

f. Mengakui dan mempromosikan regionalisme yang bertanggung jawab.

Salah satu langkah untuk mewujudkan hal ini adalah mengembangkan wilayah berbasis sektor unggulan. Meskipun menurut Nugroho dan Dahuri (2012) jika pengertian keunggulan wilayah mengacu kepada hanya ketersediaan faktor porduksi sumber daya alam (resource endowment) maka ketika teknologi mampu menggantikan sumber daya alam tersebut, dipastikan keunggulan komparatif akan berpindah mengikutial aliran modal dan migrasi. Namun mengenali faktor endowment dari suatu wilayah tetap penting mengingat Blair (1991) telah memberitahukan bahwa memahami sektor unggulan yang 
disebutunya sebagai leading economic indcators dirancang untuk mengantisipasi titik balik dalam kegiatan ekonomi daripada meramalkan nilai-nilai variabel tertentu.

Hal ini memberikan dasar kepada kita untuk tetap dan selalu mempertimbangkan sektor unggulan dalam suatu wilayah sebab fungsi utamanya yang tidak hanya memberikan infromasi mengenai sumberdaya paling potensial yang dimiliki saat ini tapi soal bagamana mengantisipasi krisis dan mengembangkan wilayah secara pasti berdasarkan besaran potensi sumber daya yang dimiliki. Untuk mengukurnya Rustiadi etl al (2011) menyatakan bahwa metode LQ (location Question) dan shift share analysis merupakan dua metdoe yang sering dipakai sebagai indikasi sektor basis yang selanjutnya digunakan sebagai indikasi sektor unggulan. Maka hal ini akan dijelaskan lebih lanjut pada bagian metode penelitian.

\section{METODE PENELITIAN}

Jenis data yang digunakan dalam penelitian ini terdiri dari data sekunder dan primer. Data sekunder meliputi: PDRB Kabupaten Gowa ADHK Tahun 2009-2013, dan jumlah produksi tanaman pertanian. Data bersumber dari publikasi Badan Pusat Statistik (BPS). Data lainnya adalah data mengenai kebijakan yang dikeluarkan pemerintah daerah Kab.Gowa baik dalam bentuk perda, perwal ataupun juknis pelaksanaan kegiatan lainnya. Data primer adalah data yang diperoleh dengan mengunjungi dan melihat langsung kondisi lapangan (Kabupaten Gowa), data ini digunakan untuk menguatkan hasil temuan dan proses analisis data sekunder, terutama pada bagian analisis deskriptif. Terdapat beberapa alat analisis yang digunakan dalam penelitian ini untuk mengetahui sektor ungggulan di Kabupaten Gowa, yaitu sebagai berikut :

1. Analisis Tipologi Klassen

Pola pertumbuhan sektor ekonomi wilayah dapat ditentukan dengan analisis Klassen Typologi melalui pendekatan sektoral. Mengamati secara sistematis laju pertumbuhan PDRB dan kontribusi PDRB per sektor, dan setelah itu diklasifikasikan kedalam kelompok/karakteristik berdasarkan Klassen Typologi. Dengan analisis Klassen Typologi dapat diketahui empat klasifikasi pertumbuhan sektor ekonomi dalam suatu wilayah yaitu; (1) Sektor yang maju dan tumbuh cepat, (2) Sektor maju tapi tertekan, (3) Sektor potensial atau masih dapat berkembang dengan pesat (sedang tumbuh) dan (4) sektor yang relatif tertinggal.

Tabel 1. Klasifikasi Tipologi Klassen

\begin{tabular}{ccc}
\hline & si $>\boldsymbol{s}$ & $\mathbf{s i}<\mathbf{s}$ \\
\hline $\mathbf{g i}>\mathbf{g}$ & "Sektor Maju dan & "Sektor Berkembang \\
& Tumbuh Cepat" & Cepat" \\
\hline $\mathbf{g i}<\mathbf{g}$ & "Sektor Maju Tetapi & "Sektor Relatif \\
& Tertekan" & Tertingggal" \\
\hline
\end{tabular}

Keterangan:

gi = Laju pertumbuhan sektoral PDRB Kabupaten Gowa

si $\quad=$ Kontribusi PDRB sektoral Kabupaten Gowa

$\mathrm{g} \quad=$ Laju pertumbuhan PDRB sektoral Provinsi Sulawesi Selatan

$\mathrm{s} \quad=$ Kontribusi PDRB sektoral Provinsi Sulawesi Selatan 


\begin{tabular}{l|l|}
\hline 1 & $\begin{array}{c}\text { JURNAL MEGA AKTIVA } \\
\text { Email : megaaktiva@febi.umkendari.ac.id } \\
\text { Website }: \text { https://megaaktiva.umkendari.ac.id/index.php/Jurnal }\end{array}$ \\
\hline
\end{tabular}

\section{Analisis LQ}

Untuk mengetahui basis ekonomi suatu wilayah digunakan pendekatan utama yaitu analisis LQ. Analsisi LQ (Location question) digunakan untuk melihat Lokasi pemusatan atau aktivitas basis dalam suau wilayah, kapasitas ekspor perekonomian suatu wilayah dan Tingkat kecukupan barang/jasa--dari produksi lokal--suatu wilayah. Model ini memliki beberapa asumsi yaitu sebagai berikut; (1) Kondisi geografis relatif seragam, (2) Pola-pola aktivitas bersifat seragam dan (3) Setiap aktivitas menghasilkan produk yang sama. Rumus model LQ adalah sebagai berikut:

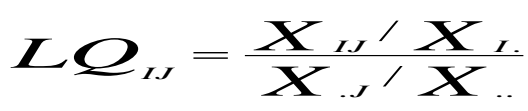

Keterangan :

Xij $=$ Nilai aktivitaske-j pada wilayahke-i,

Xi. = Jumlah seluruh aktivitas di wilayah ke-I

$X . j=$ Jumlah aktivitas ke-j di seluruh wilayah

X.. = Besaran aktivitas total di seluruh wilayah

Dari perhitungan Location Quotient (LQ) suatu sektor, kriteria umum yang dihasilkan adalah :

a) Jika LQ > 1, disebut sektor basis, yaitu sektor yang tingkat spesialisasinya lebih tinggi daripada tingkat wilayah acuan

b) Jika LQ < 1, disebut sektor non-basis, yaitu sektor yang tingkat spesialisasinya lebih rendah daripada tingkat wilayah acuan

c) Jika $\mathrm{LQ}=1$, maka tingkat spesialisasi daerah sama dengan tingkat wilayah acuan

3. Analisis Deskriptif dan Sistem Informasi Geografis (SIG)

Analisis deskriptif digunakan untuk menjabarkan hasil temuan berdasarkan analisis tipologi klassen dan LQ agar lebih mudah dipahami. Selain itu untuk menarik kesimpulan yang lebih kuat dengan memasukkan data-data kualitatif, data primer yang ditemukan ketika melakukan penelitian lapangan. Sedangkan Sistem Informasi Geografis (SIG) digunakan untuk memberikan gambaran yang jelas melalui peta mengenai sebaran komoditi unggulan di Kabupaten Gowa. Sehingga imajinasi mengenai dimana dan komoditi apa yang harus di kembangkan dalam wilayah-wilayah tertentu di Kabupaten Gowa menjadi lebih jelas

\section{HASIL DAN PEMBAHASAN}

\section{Gambaran Umum Perekonomian Kabupaten Gowa}

Penyebab ketimpangan terbesar di Provinsi Sulawesi Selatan adalah ketimpangan antar sektor yang terjadi di dalam Kabupaten/kota Perkembangan aktivitas ekonomi di Provinsi Sulawesi Selatan belum mencapai maksimal dan perkembangan setiap sektor yang cenderung kurang merata (Wajdi, 2011). Untuk kabupaten Gowa misalnya sektor utama pembentuk perekonomian didominasi oleh primary sector, lalu tertiary sector dan terkahir secondary sector. Kondisi ini tidak jauh berbeda dengan pembentuk perekonomian Provinsi Sulawesi Selatan, dimana primary sector berkontribusi paling besar terhadap perekonomian Provinsi Sulawesi Selatan seperti yang ditunjukkan dalam tabel 2 namun tampak ada kecendrungan meningkatnya kontribusi dari sektor-sektor terkait pelayanan (jasa). Hal ini juga terjadi di Kabupaten Gowa yang merupakan penciri dari akan terjadinya lompatan dalam proses transformasi ekonomi dari aktivitas ekonomi 


\section{JURNAL MEGA AKTIVA}

Email : megaaktiva@febi.umkendari.ac.id

Website : https://megaaktiva.umkendari.ac.id/index.php/Jurnal

yang didominasi sektor pertanian kemudian melompat ke sektor-sektor jasa tanpa melalui proses industrialisasi untuk pengolahan hasil-hasil pertanian.

Tabel 2. Laju Pertumbuhan PDRB dan Kontribusi PDRB Kabupaten Gowa dan Provinsi Sulawesi Selatan Tahun 2009-2013

\begin{tabular}{lcccc}
\hline \multirow{1}{*}{ Sektor } & \multicolumn{2}{c}{$\begin{array}{c}\text { Rata-Rata Laju } \\
\text { Pertumbuhan } \\
\text { PDRB }\end{array}$} & $\begin{array}{c}\text { R } \% \\
\text { Rata-rata kontribusi pdrb } \\
(\%)\end{array}$ \\
\cline { 2 - 5 } & Sulsel & Gowa & Sulsel & Gowa \\
\hline Pertanian & 4,53 & 3,58 & $27 \%$ & $44 \%$ \\
\hline $\begin{array}{l}\text { Pertambangan dan } \\
\text { penggalian }\end{array}$ & 5,39 & 16,59 & $8 \%$ & $1 \%$ \\
\hline Industri pengolahan & 7,7 & 6,62 & $14 \%$ & $4 \%$ \\
\hline Listrik,gas dan air bersih & 9,38 & 9,24 & $1 \%$ & $1 \%$ \\
\hline Konstruksi & 10,47 & 12,17 & $6 \%$ & $3 \%$ \\
\hline $\begin{array}{l}\text { Perdagangan,hotel dan } \\
\text { restoran }\end{array}$ & 10,6 & 10,18 & $17 \%$ & $15 \%$ \\
\hline $\begin{array}{l}\text { Pengangkutan dan } \\
\text { komunikasi }\end{array}$ & 12,67 & 13,76 & $9 \%$ & $7 \%$ \\
\hline $\begin{array}{l}\text { Keuangan,real estat dan } \\
\text { jasa perusahaan }\end{array}$ & 15,41 & 15,29 & $8 \%$ & $9 \%$ \\
\hline Jasa-jasa & 4,22 & 3,44 & $11 \%$ & $16 \%$ \\
\hline
\end{tabular}

Sumber: Kabupaten Gowa Dalam Angka Tahun 2009-2013 (Data diolah)

Pertanian memberikan kontribusi terbesar dalam pembentukan PDRB Kabupaten Gowa hampir 50\% berasal dari sektor pertanian. Kemudian disusul sektor jasa, perdagangan hotel dan restoran. Sementara sektor-sektor lain kontribusinya terhadap PDRB Kabupaten Gowa masih sangat rendah di bawah $10 \%$. Namun besaran kontribusi suatu sektor belum cukup memberikan gambaran mengenai pola pertumbuhan sektor ekonomi wilayah Kabupaten Gowa. Maka, dilakukan analisis Typologi Klassen dengan pendekatan sektoral yang diamati dengan menggabungkan secara sistematis terhadap laju pertumbuhan PDRB dan kontribusi PDRB per sektor, dan setelah itu diklasifikasikan kedalam kelompok/karakteristik menurut Typologi Klassen, seperti yang ditunjukkan dalam tabel 3 di bawah ini. 


\section{JURNAL MEGA AKTIVA}

Email : megaaktiva@febi.umkendari.ac.id

Website : https://megaaktiva.umkendari.ac.id/index.php/Jurnal

Tabel 3. Klasifikasi Pola Pertumbuhan Sektor Ekonomi Kabupaten Gowa Menurut Tipologi Klassen

\begin{tabular}{|c|c|c|}
\hline & $s i>\mathrm{s}$ & $s i<s$ \\
\hline & $\begin{array}{c}\text { (Sektor Maju dan Cepat } \\
\text { Tumbuh) }\end{array}$ & $\begin{array}{l}\text { (Sektor Berkembang } \\
\text { Cepat/Potensial) }\end{array}$ \\
\hline$G i>g$ & & $\begin{array}{l}\text {-Pertambangan dan penggalian } \\
\text {-konstruksi } \\
\text {-perdagangan, hotel \& restoran } \\
\text {-Pengangkutan dan komunikasi }\end{array}$ \\
\hline$g i<g$ & $\begin{array}{l}\text { (Sektor Maju Tapi Tertekan) } \\
\text {-Pertanian } \\
\text {-Keuangan, real estat dan jasa } \\
\text { perusahaan } \\
\text {-Jasa-jasa }\end{array}$ & $\begin{array}{l}\quad \text { (Sektor Relatif Tertinggal) } \\
\text {-Industri pengolahan } \\
\text {-Listrik,gas dan air bersih }\end{array}$ \\
\hline
\end{tabular}

Sumber : Hasil Analisis Olah Data

Keterangan :

gi = laju pertumbuhan PDRB sektoral Kabupaten Gowa

si $=$ kontribusi PDRB sektoral Kabupaten Gowa

$\mathrm{g}=$ laju pertumbuhan PDRB sektoral Provinsi Sulawesi Selatan

$\mathrm{s}=$ kontribusi PDRB sektoral Provinsi Sulawesi Selatan

Sejauh ini belum ada sektor maju dan tumbuh cepat di Kabupaten Gowa. Jika ingin memicu pertumbuhan ekonomi kabupaten gowa, pemerintah daerah perlu memperhatikan sektor yang potensial/berkembang cepat (sektor pertambangan dan penggalian, konstruksi, perdagangan, hotel dan restoran, serta pengangkutan dan komunikasi), yang nantinya dapat didorong menjadi sektor maju dan cepat tumbuh. Walaupun saat ini kontribusi sektor-sektor tersebut masih jauh lebih kecil dari sektorsektor lain, namun pertumbuhannya mengalami trend positif dan cenderung meningkat setiap tahunnya. Hal ini juga tidak terlepas dari posisi geografis kabupaten Gowa yang dekat dengan Kota Makassar sehingga sektor seperti perdagangan, hotel dan restoran merupakan kebutuhan masyarakat perkotaan dan terdapat beberapa area wisata di Kabupaten Gowa menyebabkan sektor ini menjadi potensial. Sementara sektor pertambangan yang juga terkategori sektor berkembang karena kebutuhan pertambangan di Kota Makassar sebagian besar dipasok dari Gowa. Pesatnya pembangunan infrastruktur dan konstruksi di Kota Makassar linier (berbanding lurus) dengan peningkatan produksi pertambangan dan penggalian di Kabupaten Gowa. Pengembangan sektor pertambangan dan penggalian sebagai sektor unggulan tidak dapat dilakukan dengan begitu saja meskipun terkategori sektor potensial secara ekonomi, karena sektor ini rentan dan sangat berdampak terhadap lingkungan yang seringkali bersifat negatif, 
oleh karena itu, perlu kehati-hatian dan analisis yang lebih jauh jika ingin mengembangan sektor ini sebagai sektor unggulan.

Kabupaten Gowa yang berbatasan Kota Makassar secara lansung menjadi wilayah penyangga sehingga sangat rentan terkena urban sprawl. Karena selama ini menurut Guastellaa dan Pareglioa (2016) bahwa proses urbanisai merupakan tantangan pembangunan berkelanjutan wilayah perdesaan. Oleh sebab itu menahan laju perluasan kota sangat penting bagi keberlanjutan wilayah Kabupaten Gowa. Maka salah satu cara untuk menekan urban sprawl adalah mempertahankan atau meningkatkan kinerja sektor pertanian. Selain itu, sebagian besar negara-negara miskin, mayoritas besar penduduk tinggal di daerah pedesaan dengan sumber mata pencaharian utamanya berasal dari pertanian (Gollin, 2010), kondisi seperti ini juga terjadi di Indonesia termaksud Kabupaten Gowa. Rata-rata penduduk miskin berada di perdesaan dengan mata pencaharian utama sebagai petani. Pada tahun 2013 berdasarkan Sensus pertanian Kab.Gowa terdapat 78.708 rumah tangga petani.

Namun kondisi saat ini menunjukkan sektor pertanian semakin tertekan dibandingkan dengan sektor lain (Tabel 2) disebabkan semakin besarnya perubahan penggunaan lahan pertanian ke non pertanian. Penelitian Ashari (2015) menunjukkan bahwa penggunaan lahan yang mengalami penurunan luasan di kawasan Mamminasata dari yang terbesar hingga yang terkecil selama periode tahun 1995-2011 secara berturutturut adalah sawah $1(18,79 \%)$, kebun $(15,31 \%)$, sawah $2(10,82 \%)$, semak belukar 1 $(2,45 \%)$, hutan $(2,00 \%)$ dan tambak $(0,63 \%)$, sementara lahan terbangun mengalami peningkatan luasan terbesar $(41,26 \%)$. Kabupaten Gowa yang menjadi bagian dari Mamminasata, suatu konsep untuk membangun wilayah metropolitan di Sualwesi Selatan menyebabkan Wilayah yang dahulunya diliputi oleh masyarakat tradisional agraris kemudian menjadi masyarakat agraris modern setelah mendapatkan pengaruh revolusi hijau di tahun 1970 kemudian beberapa dekade kembali mendapatkan sentuhan modernisasi kawasan pembangunan perkotaan, Widiatri et al (2014). Kondisi ini tentu mempengaruhi degradasi lahan pertanian akibat perubahan kebijakan, pertumbuhan ruang yang agresif disertai dengan perubahan perilaku masyarakat.

Hal diatas menunjukkan bahwa lahan-lahan untuk kerja disektor pertanian semakin mengalami penurunan sementara ruang terbangun yang dapat memicu perluasan kota semakin luas. Artinya ada kebijkan yang belum berpihak pada petani (sektor pertanian) sementara jumlah tenaga kerja yang berada di sektor ini masih cukup tinggi. Hal inilah menyebabkan pertanian sebagai sektor maju yang tertekan.

Diperlukan kebijakan untuk mengembangan sektor pertanian agar dapat mengurangi tingkat ketertekanannya sehingga dapat berkembang cepat. Hal ini penting karena sebagain besar masyarakat Gowa masih menjadikan sektor ini sebagai sumber penghidupan utama. Jika sektor ini berkembang tentu diharapkan mampu meningkatkan pendapatan petani dan akhirnya menurunkan tingkat kemiskinan. Selain itu, diharapkan tercipta multiplier effect yang lebih besar terhadap peningkatan ekonomi petani.

Maka, perlu ada kerjasama seluruh stakeholder untuk mendorong pertanian sebagai sektor yang diunggulkan. Keterlibatan aktif antara peneliti dan pemangku kepentingan lainnya (termasuk pembuat kebijakan) diperlukan sebagai upaya untuk menghasilkan strategi yang lebih sah dan berdampak untuk berkelanjutan intensifikasi (Schut et al, 2016). Intensifikasi pertanian yang berkelanjutan dan dapat meningkatkan nilai ekonomi hasil pertanian membutuhkan dukungan penelitian, tekhnologi dan pengelolaan kelembagaan pertanian yang baik. Bahkan perlu ada kebijakan khusus yang dapat 
mendorong ekstensifikasi pertanian serta meredam berbagai tekanan yang diarahkan pada sektor ini terutama alih fungsi lahan pertanian menjadi ruang terbangun.

\section{Sektor Unggulan Kabupaten Gowa}

Hasil analisis LQ menunjukkan bahwa sektor basis Kabupaten Gowa adalah sektor pertanian, sektor keuangan real estat dan jasa perusahaan, serta sektor jasa-jasa (Tabel 4). Sektor-sektor tersebut memiliki keunggulan kompetitif dan nilai kontribusi yang besar dalam perekonomian Kabupaten Gowa. Sektor ini mampu bersaing dengan daerah kabupaten/kota lain yang ada di Provinsi Sulawesi Selatan dan dapat mengekspor produknya ke wilayah lain. Temuan ini sejalan dengan hasil penelitian Ramli (2014) yang menyimpulkan bahwa sektor pertanian merupakan salah satu sektor yang perlu diperhatikan karena merupakan salah satu sektor basis. Bahkan terdapat penelitian sebelumnya yang dilakukan oleh Hasan (2003) mengenai "Model tata ruang kota tani yang berorientasi ekonomis dan ekologis" di Kabupaten Gowa. Hal ini tentu dapat mendukung penerapan sektor basis Kabupaten Gowa yang diarahkan pada sektor pertanian.

Tabel 4. Analisis LQ Kabupaten Gowa Tahun 2013

\begin{tabular}{|c|c|c|c|c|c|c|c|c|}
\hline 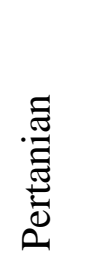 & 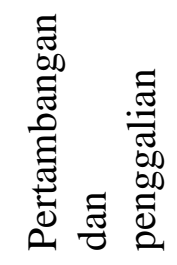 & 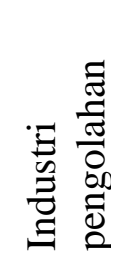 & 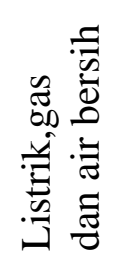 & 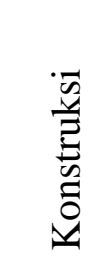 & 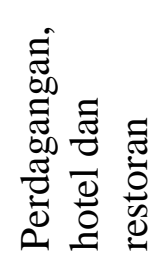 & 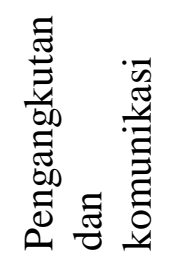 & 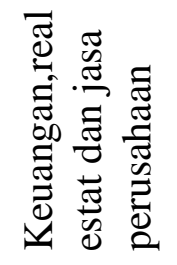 & 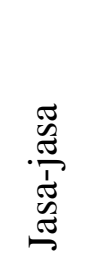 \\
\hline 1,64 & 0,11 & 0,28 & 0,97 & 0,61 & 0,87 & 0,88 & 1,16 & 1,49 \\
\hline
\end{tabular}

Sumber : Hasil Analisis Olah Data

Sektor pertanian sangat berperan penting karena sangat berpengaruh terhadap sektor lain dan perekonomian daerah di Kabupaten Gowa. Sebagian besar penduduk Kabupaten Gowa bermata pencaharian sebagai petani dengan hasil terbesar pertaniannya adalah sektor tanaman pangan berupa: padi, palawija dan tanaman holtikultura (Tabel 5). Dari penyebarannya, potensi daerah pertanian tanaman pangan terkonsentrasi di wilayah bagian timur (Kecamatan Tompobulu, Tinggimoncong, Bungaya, dan Parangloe) dengan luas $71.757,61 \mathrm{Ha}(58,51 \%)$ dari luas potensi pertanian tanaman pangan di Kabupaten Gowa (Statistik Tanaman Pangan dan Palawija Kabupaten Gowa, 2015). 


\section{JURNAL MEGA AKTIVA}

Email : megaaktiva@febi.umkendari.ac.id

Website : https://megaaktiva.umkendari.ac.id/index.php/Jurnal

Tabel 5. Kontribusi Sub Sektor Pertanian (persen)Terhadap PDRB Sektor Pertanian Kabupaten Gowa Tahun 2010-2014

\begin{tabular}{lccccc}
\hline \multicolumn{1}{c}{ URAIAN } & $\mathbf{2 0 1 0}$ & $\mathbf{2 0 1 1}$ & $\mathbf{2 0 1 2}$ & $\mathbf{2 0 1 3}$ & $\mathbf{2 0 1 4}$ \\
\hline SektorPertanian & $\mathbf{4 4 , 6 1}$ & $\mathbf{4 3 , 3 1}$ & $\mathbf{4 1 , 4 4}$ & $\mathbf{3 9 , 5 3}$ & $\mathbf{3 7 , 1 7}$ \\
& & & & & \\
Tanamanpangan & 41,63 & 40,44 & 38,72 & 36,94 & 35,17 \\
Perkebunan & 1,31 & 1,24 & 1,19 & 1,11 & 1,02 \\
Peternakan & 1,32 & 1,288 & 1,22 & 1,18 & 1,15 \\
Kehutanan & 0,12 & 0,113 & 0,11 & 0,10 & 0,10 \\
Perikanan & 0,23 & 0,216 & 0,20 & 0,19 & 0,19 \\
\hline $\begin{array}{l}\text { Sektor Non } \\
\text { Pertanian }\end{array}$ & $\mathbf{5 5 , 3 9}$ & $\mathbf{5 6 , 6 8}$ & $\mathbf{5 8 , 5 6}$ & $\mathbf{6 0 , 4 7}$ & $\mathbf{6 2 , 8 3}$ \\
\hline
\end{tabular}

Sumber: Statistik Tanaman Pangan dan Palawija, BPS Kabupaten Gowa Tahun 2015

Menetapkan pertanian sebagai komoditi unggulan cocok untuk Kabupaten Gowa jika merujuk pada kondisi topografinya berupa wilayah dataran tinggi selaus 72, $26 \%$, disertai suhu udara yang berkisar antara $18^{\circ} \mathrm{C}-30^{\circ} \mathrm{C}$. Sektor pertanian juga merupakan sektor yang lebih inklusif. Hasil penelitian Wajdi (2011) menemukan bahwa Sektor pertanian merupakan sektor yang lebih merata penyebaran aktivitasnya dibandingkan sektor lainnya di Provinsi Sulawesi Selatan. Maka sektor ini layak dijadikan unggulan karena lebih mampu meredam tingkat ketimpangan antara wilayah.

\section{Pemetaan Area Produksi Komoditi Unggulan Pertanian}

Secara gografis, tiap wilayah kecamatan di Kabupaten Gowa memiliki karakteristik yang berbeda. Karakteristik tersebut menjadikan tiap wilayah memiliki kemampuan yang berbeda dilihat dari potensi, keanekaragaman sumberdaya dan kemampuan lingkungan. Untuk dapat mengetahui keanekaragaman tingkat kemampuan lingkungan dan potensi yang dimiliki masing-masing wilayah tersebut, maka diperlukan upaya pemetaan wilayah berdasarkan potensi komoditi unggulannya. Identifikasi Komoditi unggulan sektor pertanian di Kabupaten Gowa terdapat di Tabel 6 di bawah ini.

Tabel 6. Komoditi Unggulan Sektor Pertanian Kabupaten Gowa

\begin{tabular}{cll}
\hline Sektor Pertanian & \multicolumn{1}{c}{ Komoditi Unggulan } & \multicolumn{1}{c}{ Wilayah Produksi } \\
\hline Sub sektor tanaman pangan & Padi, jagung, umbi-umbian & Kecamatan: Parangloe, \\
& & Manuju, \\
& Bontolempangan, \\
& Pattallassang, Parigi, \\
& Biringbulu, Sombaopu, \\
& Pallangga, \\
& Bontomarannu, Bajeng, \\
& Bajeng Barat, \\
& Bontonompo, \\
\hline
\end{tabular}




\section{JURNAL MEGA AKTIVA}

Email : megaaktiva@febi.umkendari.ac.id

Website : https://megaaktiva.umkendari.ac.id/index.php/Jurnal

\begin{tabular}{|c|c|c|}
\hline & & $\begin{array}{lr}\text { Bontonompo } & \text { Selatan, } \\
\text { Tombolo } & \text { pao, } \\
\text { Tompobulu. } & \\
\end{array}$ \\
\hline Sub sektor perkebunan & $\begin{array}{lrr}\text { Kakao, } & \text { Kopi } & \text { Robusta, } \\
\text { Panili, } & \text { Lada, } & \text { Kemiri, } \\
\text { kelapa, } & \text { Cengkeh, }\end{array}$ & $\begin{array}{l}\text { Kecamatan: Bungaya, } \\
\text { Tinggimoncong, Biring } \\
\text { bulu, Tompobulu. }\end{array}$ \\
\hline $\begin{array}{l}\text { Sub sektor peternakan dan } \\
\text { Perikanan }\end{array}$ & $\begin{array}{l}\text { Babi, kambing, kuda, ayam } \\
\text { buras, ikan, itik }\end{array}$ & $\begin{array}{l}\text { Kecamatan: } \\
\text { Tinggimoncong, } \\
\text { Biringbulu, } \\
\text { Barombong, } \\
\text { Sombaopu, Pallangga, } \\
\text { Bontomarannu, Bajeng, } \\
\text { Bajeng } \\
\text { Bontonompo, Barat, } \\
\text { Bontonompo selatan, } \\
\text { Tombolo } \\
\text { Tompobulu }\end{array}$ \\
\hline
\end{tabular}

Sumber: Kabupaten Gowa Dalam AngkaTahun 2015 (Data diolah)

Pemetaan terhadap komoditi unggulan di Kabupaten Gowa akan mampu mengestimasi seberapa besar potensi pengembangan komoditi unggulan di wilayah tersebut. Seperti yang disampaikan oleh Kempenaar et al, (2016) bahwa dalam desain wilayah biasanya terdiri dari peta dan ilustrasi yang mewakili masa depan yang diinginkan untuk suatu daerah. Potensi pengembangan komoditi yang telah diketahui nantinya akan menjadi majory force dalam mengurangi disparitas antar wilayah di Kabupaten Gowa. Pelaksanaan pemetaan terhadap potensi pengembangan komoditas pertanian lebih lanjut dapat menciptakan keselarasan antara kemampuan daya dukung (carrying capacity) lingkungan dengan besaran upaya pengembangan sektor pertanian yang akan dilakukan sehingga terwujud pembangunan yang berkelanjutan (sustainable development) dan berwawasan lingkungan (Romadhon dan Sucipto, 2010).

Pemetaan/mapping area produksi komoditi unggulan di Kabupaten Gowa dapat dilihat pada Gambar berikut: 


\section{TMA JURNAL MEGA AKTIVA \\ Email : megaaktiva@febi.umkendari.ac.id \\ Website : https://megaaktiva.umkendari.ac.id/index.php/Jurnal}

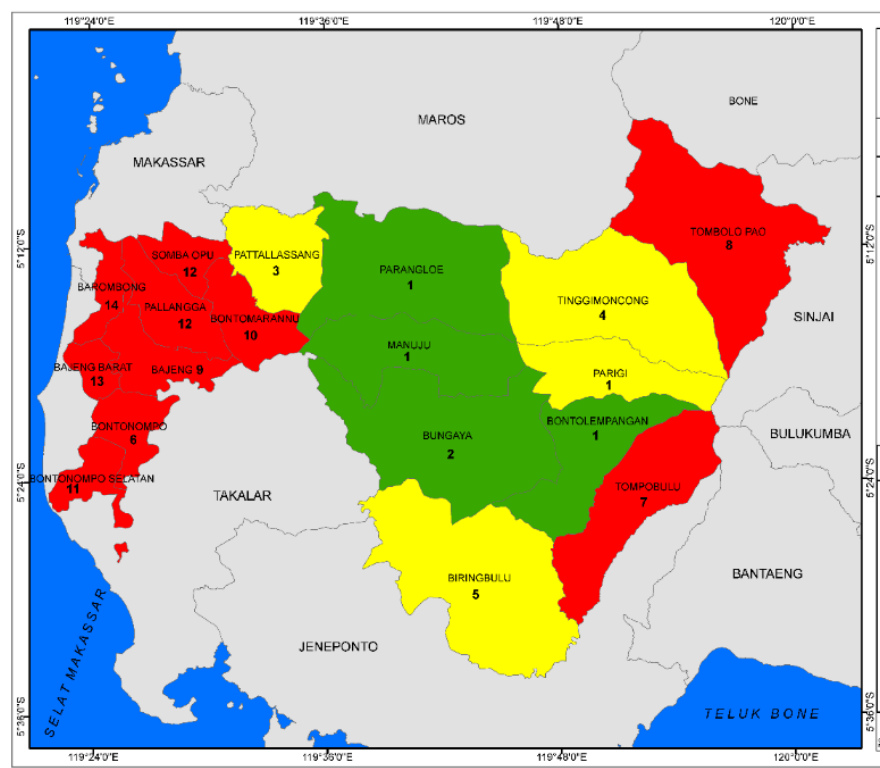

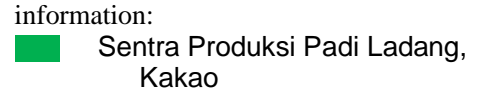

information:

Sentra Produksi Padi Ladang, Kakao

Sentra Produksi Padi Ladang, Ternak babi, kopi robusta, vanili, kemiri, getah, ternak kambing, jambu mente, kelapa, padi ladang

Sentra produksi Padi sawah, ayam ras pedaging, itik, ikan, padi ladang, sapi, ikan, ayam ras petelur, kerbau

\section{Gambar 1}

Sebaran Sentra Produksi Komoditi Unggulan Di Kabupaten Gowa Menggunakan Sistem Informasi Geografis (SIG)

Hasil pemetaan komoditi unggulan dapat dijadikan acuan bagi pemerintah daerah khususnya instansi-instansi terkait seperti Bappeda, Dinas Pertanian dalam menyusun rencana kegiatan penyuluhan pertanian di Kabupaten Gowa. Optimalisasi kegiatan penyuluhan dapat disusun berdasarkan hasil pemetaan komoditi unggulan masing-masing wilayah. Sehingga pengembangan komoditi unggulan dapat didasarkan dari kemampuan produktivitas suatu komoditi dan terutama yang merupakan komoditas lokal agar dapat memperkaya dan membangkitkan kembali potensi komoditas, tanpa memaksakan suatu komoditas yang tidak sesuai dengan kondisi lahan serta kebiasaan masyarakat setempat.

\section{KESIMPULAN}

Pengklasifikasian sektor-sektor di Kabupaten Gowa berdasarkan Tipologi Klassen ternyata tidak ada satupun sektor yang terkategori "Sektor Maju dan Cepat Tumbuh" namun terdapat beberapa sektor yang "Berkembang Cepat/Potensial yaitu"; 1). Pertambangan dan penggalian, 2). Konstruksi 3). Perdagangan, hotel \& restoran dan 4). Pengangkutan dan komunikasi. Namun sektor-sektor ini membutuhkan penggunana lahan yang luas, terutama untuk ruang terbangun sehingga dapat memicu percepatan konversi lahan, sehingga mempunyai resiko yang tinggi terhadap perubahan ruang dan lingkungan. Selanjutnya sektor yang terkategori "Maju Tapi Tertekan" adalah; 1) Pertanian, keuangan, 2) Real estat dan jasa perusahaan, dan 3) Jasa-jasa. Meskipun tertekan namun sektor-sektor ini mempunyai peluang untuk dikembangkan seperti sektor jasa karena beberapa tempat di Kabupaten Gowa secara alamiah potensial menjadi kawasan ekowisata yang dapat memicu kembali perkambangan sektor jasa dan terlebih karena posisi geografisnya yang dekat dengan kota besar (Makassar). Sektor pertanian masih dapat memainkan peraa 
penting dalam pengembangan wilayah Kabupaten Gowa karena sebagian besar penduduknya masih bergantung pada sektor ini, dan berdasarkan hasil analisis LQ terkategori sebagai sektor unggulan.

Sektor unggulan di kabupaten Gowa adalah: Sektor pertanian, sektor keuangan, real estat dan jasa perusahaan serta sektor jasa-jasa. Sentra produksi komoditi unggulan pertanian di Kabupaten Gowa tersebar hampir di seluruh wilayah kecamatan, dengan produksi terbesar di subsektor tanaman pangan. Perlu ada kebijakan khusus dari pemerintah daerah yang responsif atas penemuan ini agar produksi tanaman pangan tetap terjaga bahkan mengalami peningkatan kualitas atau perluasan areal tanam. Mengingat alih fungsi lahan pertanain yang semakin luas dan posisi geografis Kabupaten Gowa sebagai wilayah penyanggah Kota Makassar rentan mengalami urban sprawl sehingga dapat menghalangi penetapan pertanian sebagai sektor basis.

Pengembangan sektor unggulan di Kabupaten Gowa sangat diperlukan untuk mempercepat pertumbuhan ekonomi dan mengurangi disparitas antar wilayah di Kabupaten Gowa dan menurunkan tingkat kemiskinan. Pemerintah daerah perlu melakukan pengembangan komoditi unggulan sektor pertanian, dengan fokus utama peningkatan produktivitas hasil pertanian. Sedangkan untuk mempercepat akselerasi pertumbuhan ekonomi dapat dilakukan dengan mengembangkan sektor potensial yang pertumbuhan sektornya mengalami trend positif selama beberapa tahun terakhir namun dengan catatan "tanpa mengabaikan aspek lingkungan" yang mungkin saja muncul sebagai akibat pandangan positivistik yang hanya mengejar nilai ekonomi. Oleh sebab itu peneliti menyarankan dalam setiap paket pengembangan kebijakan wilayah di Kabupaten Gowa berdasarkan sektor unggulan dan mempertimbangkanserta menghitung aspek sosialekologi.

\section{DAFTAR PUSTAKA}

Antonescu D, 2012. Identifying regional disparities in Romania: a convergence process perspective in relation to European Union's territorial structures. Procedia Economics and Finance 3 ( 2012 ) 1148 - 1155

Ashari, A. F, 2015. Analisis Perubahan Penggunaan Lahan Dengan Aplikasi Model Clue-S Untuk Arahan Pemanfaatan Ruang Di Kawasan Strategis Nasional Mamminasata, Sulawesi Selatan. Tesis. Institute Pertanian Bogor. Bogor.

Badan Pusat Statistik Kabupaten Gowa. 2015. Statistik Tanaman Pangan dan Palawija Kabupaten Gowa Tahun 2015. Gowa.

Badan Pusat Statistik Kabupaten Gowa, 2015. Kabupaten Gowa Dalam Angka Tahun 2015. Gowa.

Badan Pusat Statistik Kabupaten Gowa, 2013. Sensus Pertanian Kabupaten Gowa. Gowa.

Badan Perencanaan Pembangunan Nasional, 2008. Hambatan Perdagangan Antar Daerah dan Dampaknya Terhadap Perekonomian Daerah. Bappenas. Jakarta.

Bakri, R. F. Ali, M. Natalia V. V, 2016. Disparitas Pembangunan antar Wilayah Makassar, Maros, Gowa, dan Takalar. Prosiding Temu Ilmiah IPLBI.

Blair JP, 1991. Urban and Regional Economics. Irwin. Boston.

Gollin D, 2010. Agricultural Productivity and Economic Growth. Handbook of Agricultural Economics, Volume 4 


\section{JURNAL MEGA AKTIVA}

Email : megaaktiva@febi.umkendari.ac.id

Website : https://megaaktiva.umkendari.ac.id/index.php/Jurnal

Guastellaa G., Pareglioa S. 2016. Sustainable development of rural areas: using urban patterns to map the agricultural systems. Agriculture and Agricultural Science Procedia 8 ( 2016 ) $88-98$

Ismail., Syafitri. 2005. Model Pengembangan Agroindustri Unggulan Untuk Memperkuat Daya Saing Daerah. Jurnal Tema. Vol.6, No 1.

Kempenaar A, Westerink J, Lieropa VM, Brinkhuijsena M, Brinkc DVA, 2016. "Design makes you understand"-Mapping the contributions of designing to regional planning and development. Landscape and Urban Planning .149 (2016) 20-30

Mukhyi, Mohammad Abdul, 2007, Analisis Peranan Subsektor Pertanian dan Sektor Unggulan Terhadap Pembangunan Kawasan Ekonomi Propinsi Jawa Barat. Simposium Nasional RAPI VI. Depok.

Nindyantoro. 2004. Kebijakan Pembangunan Wilayah: Dari Penataan Ruang Sampai Otonomi Daerah. Jurusan Sosial Ekonomi Pertanian Fakultas Pertanian. IPB. Bogor.

Nugroho I dan Dahuri R. 2012. Pembangunan Wilayah Perspektif Ekonomi, Sosial dan Lingkungan. LP3ES. Jakarta.

Nurzaman SS. 2012. Perencanaan Wilayah dalam Konteks Indonesia. Penerbit ITB. Bandung.

Prahastha dan Santoso. 2014. Pengembangan Komoditas Unggulan Sektor Pertanian tanaman Pangan di Kabupaten Karangasem Melalui Pendekatan Agribisnis. Surabaya. Jurnal Teknik Pomits. Vol.3, No.2.

Ramli, A. 2014. Analysis of potential economic sector on Gowa District, Indonesia. Archieves of Business Research - Vol.2,NO.6.

Romadhon., Sucipto. 2010. Pemetaan Potensi Komoditas dan Rancangan Pengembangan di Kecamatan Blega Bangkalan Madura. Bangkalan. Jurnal Agrovigor. Vol. 3, No.2

Rustiadi E, Saefulhakim S., Panuju DR, 2011. Perencanaan dan Pengembangan Wilayah. Yayasan Pustaka Obor Indonesia. Bogor.

Schut M, Asten VP, Okafor C, Hicintuka C, Mapatano S , Nabahungu LN , KagaboD , Muchunguzi P, 2016. Sustainable intensification of agricultural systems in the Central African Highlands: The need for institutional innovation. Agricultural Systems 145 (2016) 165-176

Sub Direktorat Basis Data Lahan. 2014. Kajian Hasil Inventarisasi LP2B Kabupaten Gowa Provinsi Sulawesi Selatan. Kementerian Pertanian.

Wajdi, F, 2011. Analisis Ketimpangan Pembangunan Provinsi Sulawesi Selatan. Tesis Institute Pertanian Bogor. Bogor.

Widiatri AR, Dharmawan AH, dan Kinseng AR, 2014. Pengaruh Pembangunan Mamminasata Terhadap Perubahan Sosial Ekonomi dan Ekologi Pada Masyarakat Lokal. Jurnal Sodality, Agustus 2014, hlm : 103-114 